\title{
ANALYZING DYSFUNCTIONAL BEHAVIORS IN THE CASES OF LAO AND VIETNAMESE RESTAURANTS
}

\author{
Sengthong Vongphachanh
}

$T N U$ - International School

\begin{tabular}{|c|c|c|}
\hline \multicolumn{2}{|c|}{ ARTICLE INFO } & ABSTRACT \\
\hline Received: & $16 / 4 / 2021$ & This study focused on exploring the factors impacting dysfunctional \\
\hline Revised: & $21 / 5 / 2021$ & $\begin{array}{l}\text { behaviour and testing the difference of perceptions between Laotian } \\
\text { and Vietnamese consumer behaviour towards restaurant service. }\end{array}$ \\
\hline Published: & $24 / 5 / 2021$ & Several hypotheses were proposed based on consumer characteristics \\
\hline & & that could foster dysfunctional behavior. For this, an hybrid \\
\hline \multicolumn{2}{|l|}{ KEYWORDS } & methodology was used in order to develop the questionnaire; besides, \\
\hline \multicolumn{2}{|l|}{ Dysfunctional } & Respondents were asked to rate the appropriateness of each behavior \\
\hline \multicolumn{2}{|l|}{ Consumer behavior } & and answer a group of questions based on the developed hypothesis \\
\hline \multicolumn{2}{|l|}{ Aggressive } & developed. The data was collected over the Internet (Facebook and \\
\hline \multicolumn{2}{|l|}{ Moral flexibility } & $\begin{array}{l}\text { online access) and the statistical methods used for analyzing were } \\
\text { regression, EFA and CFA analysis. The results showed evidence that }\end{array}$ \\
\hline \multicolumn{2}{|l|}{ Machiavellianism } & interpersonal influence, such as aggressiveness, self-exposure, moral \\
\hline \multicolumn{2}{|l|}{ Dissatisfaction } & $\begin{array}{l}\text { flexibility and machiavellianism, and situational aspects, such as } \\
\text { dissatisfaction and acceptance, impacted significantly on dysfunctional } \\
\text { behavior and there was a difference of perception between Laotian and } \\
\text { Vietnamese consumer behavior towards restaurant service. }\end{array}$ \\
\hline
\end{tabular}

\section{PHÂN TÍCH HÀNH VI RỐI LOẠN CHỨC NĂNG TRONG CÁC NHÀ HÀNG LÀO VÀ VIẸTT NAM}

Sengthong Vongphachanh

Khoa Quốc tế - ĐH Thái Nguyên

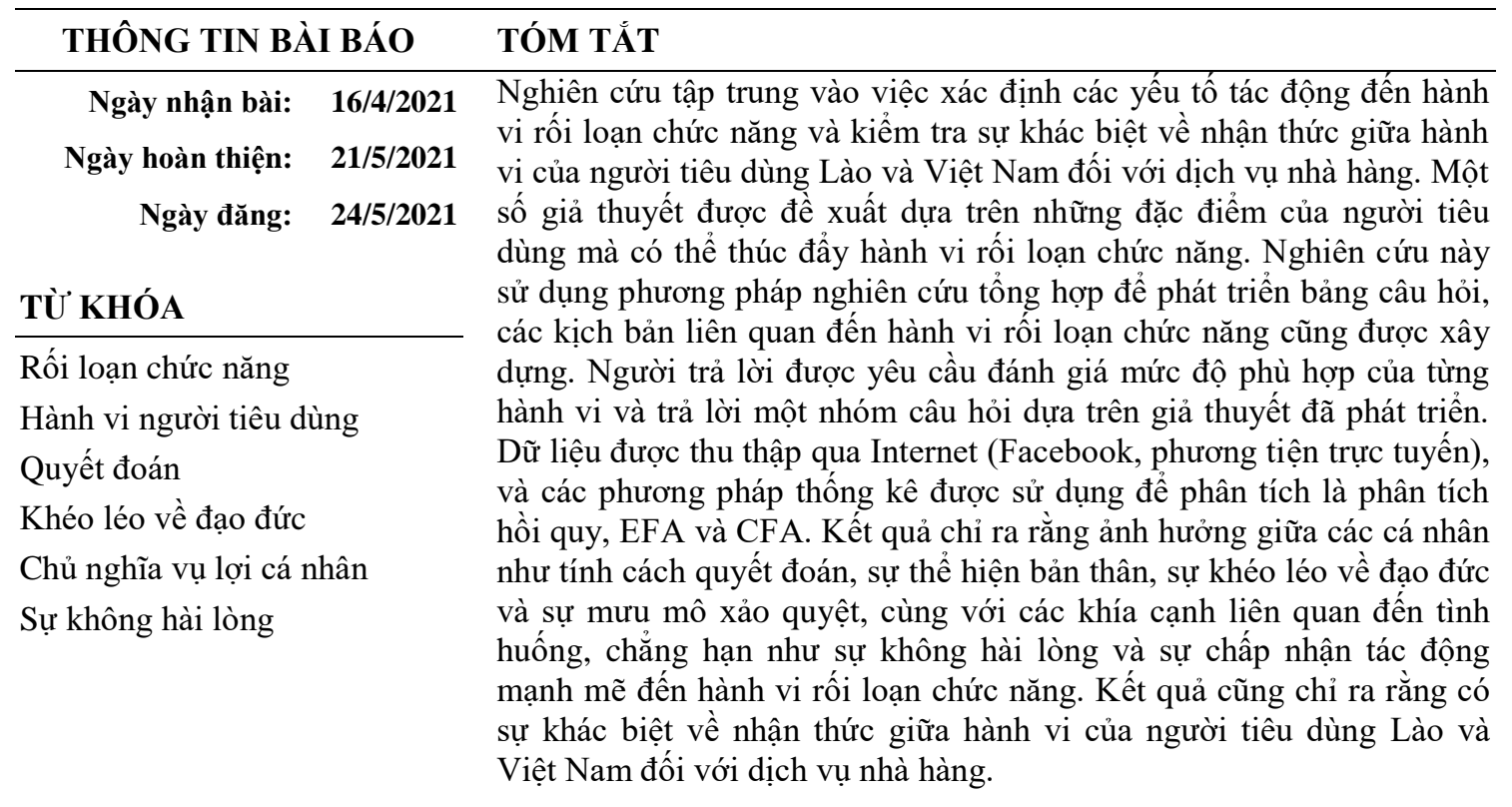

DOI: https://doi.org/10.34238/tnu-jst.4377

Email: sengthong.mook98@gmail.com 


\section{Introduction}

The belief that the customer is always the right person is completely significant to complete a speech of common sense [1]. However, this statement is not really logical, as the results it can lead to rationalize the dysfunctional consumer behavior [2], which can be aware as the behaviour adopted by certain consumers who are against the rules and regulations established by the society in which they are inserted, during the consumption of a product and/or service [3].

Dysfunctional customer behaviour is endemic and prevalent across multiple service industry and is a growing issue for employees and organizations [1]. For instance, some customers treat employees with unfriendly attitude, verbal abuse or violence and bullying, damage to facilities, noisy, crowded, queue jumping and other acts. Employees who work at a call centre encounter dysfunctional customer behaviour averagely ten times a day [4]. In other studies, $74 \%$ of airline and railway employees revealed that they experienced dysfunctional customer behavior once a month [5], and $82 \%$ of hotel and restaurant employees confirmed that they had been the target of dysfunctional customer behavior [1]. They have not only a negative impact on business management and the customer service experience, but also great harm to physical and mental health of employees.

Significant interest from practitioners and scholars, understanding of the concept of dysfunctional customer behaviour and its measurement is limited, and the existing dysfunctional customer behaviour scale does not offer extensive evidence of validity [6]. Moreover, to date, studies have not systematically explored the exact dimensionality of dysfunctional customer behavior, leaving its precise composition unclear in specifically both Laos and Vietnam. Thus, to advance research on the factors impacting dysfunctional customer behaviour in case Lao and Vietnamese restaurants, a comprehensive measure is needed to assess a set of behavior characteristics that influence dysfunctional consumer behavior and the difference of perceptions between Lao and Vietnamese customers. A valid, reliable scale that measures dysfunctional customer behaviour could provide important insights to marketing scholars and managers about the nature of this critical aspect of customer behavior.

In order to build a proper and sufficient dysfunctional consumer behavior research, a proper research problem is defined and squeezed into 2 main questions following to help understand the goal of the research.

- What are factors impacting dysfunctional consumer behavior in the restaurant industry?

- What is statistically difference of perceptions between Lao and Vietnamese consumer behavior?

This research seeks to find answers to:

- Explore and understand the factors impacting dysfunctional behaviour

- Test the difference of perceptions between Lao and Vietnamese consumer behaviour for restaurant service

- Suggest implications for restaurant owners to improve dysfunctional consumer behavior.

\section{Methods}

As illustrated in figure 1, the variables regarding the individual's personality considered for the development of the model are: aggression, self-exposure, moral flexibility and machiavellianism. The situational variables are dissatisfaction and acceptance. It is expected that they all have a positive impact on the dysfunctional consumer behavior. The stronger they are, the higher the probability of the individual to act inappropriately.

- Hypothesis 1: the aggressiveness has positive impact on dysfunctional consumer behavior.

- Hypothesis 2: the self-exposure has positive impact on dysfunctional consumer behaviour.

- Hypothesis 3: Moral flexibility has positive impact on dysfunctional consumer behaviour.

- Hypothesis 4: Machiavellianism has positive impact on dysfunctional consumer behaviour. 
- Hypothesis 5: Situational aspects have positive impact on dysfunctional consumer behaviour.

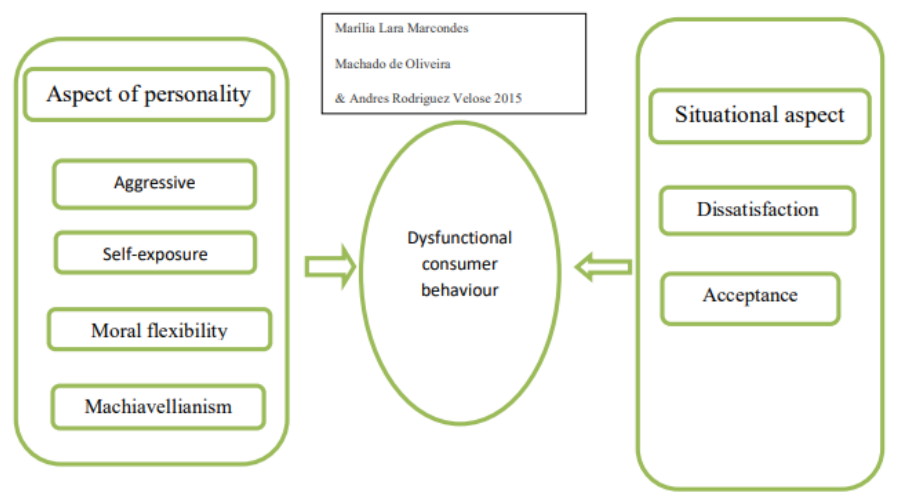

Figure 1. Conceptual framework

One of the main characteristics of the target population is that the data sample can be collected from Lao and Vietnamese consumers in restaurant service. This research included respondents from both countries, but the majority were Vietnamese. With regard to the gender, the sample of this research was calculated by using Cochran's formula (1977) for calculating sample size when the population is infinite with $95 \%$ confidence level.

$$
\mathrm{N}=\mathrm{p}(1-\mathrm{p}) \mathrm{z}^{2} / \mathrm{e}^{2}
$$

In this study, $\mathrm{P}=0.1 ; \mathrm{Z}=2.58 ; \mathrm{e}=0.05$. Therefore,

$$
\mathrm{N}=(0.1)(1-0.1)\left(2.58^{2)} /\left(0.05^{2)}=240\right.\right.
$$

After calculated the sample size by substituting the numbers into the Cochran's formula (1) to obtain reliability of data, the sample size was increased to 266 respondents. The sample included women and men. The average age of respondents was from 18 to 29 years old because they are easy to access the information through social media.

The research used the Likert scale $(1=$ strongly agree to, $5=$ strongly disagree $)$, where respondents indicated their level of agreement with a range of statements. The responses were scored from 1 to 5 and the highest result score for each statement indicated the level of agreement with the statement. The result of the study was analysed through regression and correlation. The data was processed through Statistical Package for the Social Sciences (SPSS) to get the outcome. In order to identify which individuals could behave in a dysfunctional manner or not, 22 statements were for personality aspect and 4 stories were developed of situations faced in the day-to-day by consumers and two dysfunctional reaction for each situation, totally 8 dysfunctional behaviours. The developed stories involved both the issue of dissatisfaction and the influence of others. After reading the stories, the respondents were asked to analyse their reactions for the situation presented. It is understood, therefore, that the individuals who believed that the reactions were appropriate would be those most prone to act opportunistically.

\section{Results and discussion}

\subsection{Demographic characteristics}

The gender characteristics clearly stipulates that $27.8 \%$ of the respondents were males whiles $72.2 \%$ were female and missing data accounted for an insignificant figure of $0 \%$. However, it must be noted that the difference in the number of respondents between the males and females is not significant for this study. The nationality characteristic of the population of study revealed that $46.2 \%$ of the respondents were from Laos; $53.8 \%$ were from Vietnam. 


\subsection{Analyze the possible factors that could impact dysfunctional consumer behavior}

Hypothesis 1: the aggressiveness has positive impact on dysfunctional consumer behavior.

The results in Table 1 shows that the model had an R-Squared value of 0.349 meaning only approximately $34 \%$ of the variations in the relation of aggressive and dysfunctional consumer explained. $\mathrm{F}=140.197, \mathrm{p}=0.00$ which were used to test the significance of the entire model by taking all the coefficients together shows that it is significant at $\mathrm{P}<0.05$. Therefore, hypothesis $\mathrm{H} 1$ is accepted.

Table 1. Model summary of aggressive

\begin{tabular}{|c|c|c|c|c|c|c|c|c|c|c|}
\hline & \multirow[b]{3}{*}{$\mathbf{R}$} & \multicolumn{8}{|c|}{ Model Summary $^{\text {b }}$} & \multirow{3}{*}{$\begin{array}{l}\text { Durbin- } \\
\text { Watson }\end{array}$} \\
\hline \multirow[b]{2}{*}{ Model } & & \multirow{2}{*}{$\begin{array}{c}\text { R } \\
\text { Square }\end{array}$} & \multirow{2}{*}{$\begin{array}{l}\text { Adjusted } \\
\text { R Square }\end{array}$} & \multirow{2}{*}{$\begin{array}{c}\text { Std. Error } \\
\text { of the } \\
\text { Estimate }\end{array}$} & \multicolumn{5}{|c|}{$\begin{array}{r}\text { Change Statistics } \\
\end{array}$} & \\
\hline & & & & & $\begin{array}{c}\text { R Square } \\
\text { Change }\end{array}$ & $\begin{array}{c}F \\
\text { Change }\end{array}$ & df1 & $d f 2$ & $\begin{array}{c}\text { Sig. } F \\
\text { Change }\end{array}$ & \\
\hline 1 & $0.590^{\mathrm{a}}$ & 0.349 & 0.346 & 0.78768 & 0.349 & 140.197 & 1 & 262 & 0.000 & 1.998 \\
\hline
\end{tabular}

a. Predictors: (Constant), AGRESSIVE

b. Dependent Variable: dysfunctional consumer behavior

Hypothesis 2: the self-exposure has positive impact on dysfunctional consumer behavior.

As shown in Table 2, the model had an R-Squared value of 0.042 meaning only approximately $4.2 \%$ of the variations in the relation of self-exposure and dysfunctional consumer explained. $\mathrm{F}=11.550, \mathrm{p}=0.001$ which were used to test the significance of the entire model by taking all the coefficients together shows that it is significant at $\mathrm{P}<0.05$. Therefore, Hypothesis $\mathrm{H} 2$ is accepted.

Table 2. Model summary of self-exposed

\begin{tabular}{|c|c|c|c|c|c|c|c|c|c|c|}
\hline \multicolumn{11}{|c|}{ Model Summary ${ }^{b}$} \\
\hline \multirow[b]{2}{*}{ Model } & \multirow[b]{2}{*}{$\mathbf{R}$} & \multirow{2}{*}{$\begin{array}{c}\mathbf{R} \\
\text { Square }\end{array}$} & \multirow{2}{*}{$\begin{array}{l}\text { Adjusted } \\
\text { R Square }\end{array}$} & \multirow{2}{*}{$\begin{array}{c}\text { Std. Error } \\
\text { of the } \\
\text { Estimate }\end{array}$} & \multicolumn{5}{|c|}{$\begin{array}{r}\text { Change Statistics } \\
\end{array}$} & \multirow{2}{*}{$\begin{array}{l}\text { Durbin- } \\
\text { Watson }\end{array}$} \\
\hline & & & & & $\begin{array}{c}\text { R Square } \\
\text { Change }\end{array}$ & $\begin{array}{c}F \\
\text { Change }\end{array}$ & $d f 1$ & $d f 2$ & $\begin{array}{c}\text { Sig. } F \\
\text { Change }\end{array}$ & \\
\hline 1 & $0.205^{\mathrm{a}}$ & 0.042 & 0.039 & 0.95511 & 0.042 & 11.550 & 1 & 262 & 0.001 & 1.586 \\
\hline
\end{tabular}

a. Predictors: (Constant), self-exposed

b. Dependent Variable: dysfunctional consumer behavior

Hypothesis 3: Moral flexibility has positive impact on dysfunctional consumer behaviour.

The results shows that the model had an R-Squared value of 0.515 meaning only approximately $51.5 \%$ of the variations in the relation of moral flexibility and dysfunctional consumer explained. $\mathrm{F}=263.479, \mathrm{p}=0.000$ which were used to test the significance of the entire model by taking all the coefficients together shows that it is significant at $\mathrm{P}<0.05$. Therefore, hypothesis $\mathrm{H} 3$ is accepted.

> Hypothesis 4: Machiavellianism has positive impact on dysfunctional consumer behaviour.

The result shows the model had an R-Squared value of 0.263 meaning only approximately $26.3 \%$ of the variations in the relation of Machiavellianism and dysfunctional consumer explained. $\mathrm{F}=91.561, \mathrm{p}=0.000$ which were used to test the significance of the entire model by taking all the coefficients together shows that it is significant at $\mathrm{P}<0.05$. Therefore, Hypothesis $\mathrm{H} 4$ is accepted.

Hypothesis 5: Situational aspects have positive impact on dysfunctional consumer behaviour.

The results shows that the model had an R-Squared value of 0.617 meaning only approximately $61.7 \%$ of the variations in the relation of situational aspects and dysfunctional consumer 
explained. $\mathrm{F}=405.676, \mathrm{p}=0.000$ which were used to test the significance of the entire model by taking all the coefficients together shows that it is significant at $\mathrm{P}<0.05$. Therefore, hypothesis H5 is accepted.

\subsection{Statistical difference of perceptions between Lao and Vietnamese consumer behavior}

H0: there is no difference of perceptions between Lao and Vietnamese consumer behaviour.

$\mathrm{H} 1$ : there is the difference of perceptions between Lao and Vietnamese consumer behaviour.

As a result of t test analysis conducted on the effects of nationalities (Lao and Vietnamese customers) on personality aspects and situational aspects, there were differences of the prospective of Lao and Vietnam consumers in both personality aspects and situational aspects. Interestingly, dysfunctional consumer behaviour indicates that the respondents both in Laos and Vietnam were significantly and positively influenced by the nationality in aggressiveness, self exposed, moral flexibility, machiavellianism and situational aspects. All of the aspects had a sig. less than 0.05 indicating that it has a positive impact to dysfunctional consumer behaviour. Therefore, $\mathrm{H} 1$ is accepted.

\section{Conclusion and recommendation}

\subsection{Conclusion}

It was possible to note from the study that the personality characteristics seem to positively influence the social undesirable consumer behaviour. Among the four studied aspects, apparently moral flexibility and machiavellianism were those with the greatest impact on behaviour. The aggressiveness was defined by this study as the status of the person who tended to cause damage to others, as a result, it needs to be avoided. Besides, moral flexibility was defined as in case they could make a decision on how to act when facing with an ethical dilemma. The machiavellian individual can be understood as the one who seeks to manipulate other people, understanding that such manipulation is simply a means to reach an end. When these two definitions are compared to that of dysfunctional behaviour, it can be seen that the result obtained supports the theory. The situational issues in this research were placed to individuals in the form of stories. However, in this research, the individuals in the group with the greatest tendencies to act in dysfunctional manner appeared. The analysis of the level of acceptance of the inappropriate reactions described in the stories for each group showed that the more people are with the individual, the more appropriate is his behaviour.

One last important point to be discussed is what the difference of the Lao and Vietnamese customers' perception on dysfunctional behaviour. We achieved the main purpose of this study, which was to identify what factors effect to dysfunctional consumer behavior and the result shows that nationalities have positive impact on both personality and situational aspects.

As the result, we can see that both aspects can affect dysfunctional consumer behavior. The data was collected over the Internet (Facebook and online access) and the statistical methods used for analyzing were SPSS , EFA and CFA analysis. The results showed evidence that it was confirmed that interpersonal influence, such as aggressiveness, self-exposure, moral flexibility and machiavellianism, and situational aspects, such as dissatisfaction and acceptance impacted significantly on dysfunctional behavior and there was a difference of perception between Lao and Vietnamese consumer behavior for restaurant service.

\subsection{Recommendation}

The current research provides an interesting exploratory insight into the causes of dysfunctional customer behavior and the difference of perceptions between Laotian and Vietnamese consumer behavior. The result of the research was restricted by the feature and aspect of the research. This could lead to a significant attractive way for future research. Firstly, 
to upgrade generalizability, the important evaluation and later experiment are required to shape the advanced proposition in order to measure the extent to which the improved framework is reliable and reasonable. Secondly, the concentration of this research has been on just Laotian and Vietnamese restaurants, and much of the behavior and causes uncovered are likely to be specific to such contexts (and possibly even specific to contexts where alcohol is served in those restaurant). Future studies can explore these phenomena in alternative contexts and within the food and service industry.

\section{Acknowledgement}

I would like to take this opportunity to express sincere thanks to my supervisor, Prof. Tu Anh. It has been an honour to be guided by you. I am in deep gratitude for your placing great attention and interest on this project. Without your assistance, patience and dedication in every step throughout this process, this paper would have never been accomplished. Thank you so much for all your support.

\section{REFERENCES}

[1] L. C. Harris and K. L. Reynolds, “The Consequences of Dysfunctional Customer Behaviour," Journal of Service Research, vol. 6, no. 2, pp. 144-161, 2003.

[2] R. A. Fullerton and G. Punj, "Repercussions of promoting an ideology of consumption: consumer misbehavior," Journal of Business Research, vol. 57, no. 11, pp. 1239-1249, Nov. 2004.

[3] R. P. Fisk, L. C. Harris, S. Grove, D. Greer, K. Daunt, R. Russell-Bennett, and J. Wirtz, "Customers behaving badly: a state of the art review, research agenda and implications for practitioners," Journal of Services Marketing, vol. 24, no. 6, pp. 417-429, 2010.

[4] A. A. Grandey, D. N. Dickter, and H-P. Sin, "The customer is not always right: customer aggression and emotion regulation of service employees," Journal of Organizational Behavior, vol. 25, no. 3, pp. 397- 418, 2002.

[5] C. Boyd, "Customer Violence and Employee Health and Safety," Journal of Work Employment \& Society, vol. 16, no. 1, pp. 151-169, 2002.

[6] P. Dabholkar, C. Shepherd, and D. Thorpe, "A Comprehensive Framework for Service Quality: An Investigation of Critical Conceptual and Measurement Issues through a Longitudinal Study," Journal of Retailing, vol. 76, no. 2, pp. 139-73, 2000. 